\title{
Um indicador de não satisfação no trabalho e a mobilidade do mercado de trabalho:
}

um estudo para homens e mulheres

\author{
Danielle Carusi Machado* \\ Adriana Fontes da Silva**
}

\author{
Palavras-chave \\ não satisfação no \\ trabalho, gênero, trabalho, \\ transições ocupacionais, \\ mercado de trabalho.

\section{Classificação JEL \\ j28, J16, J63. \\ Keywords \\ non job satisfaction, gender, labor, occupational transitions, labor market.}

\section{JEL Classification \\ J28, J16, J63.}

\footnotetext{
*Professora Adjunta da Faculdade de Economia da UFF e Pesquisadora do CEDE/UFF

**Economista sênior da Macroplan e pesquisadora do Instituto de Estudos do Trabalho e Sociedade (Iets)
}

\section{Resumo}

Existem evidências na literatura internacional de que medidas de não satisfação no trabalho podem funcionar como boas preditoras para as saídas do mercado de trabalho. Desta forma, essas medidas seriam informativas para o entendimento das diferenças de mobilidade no mercado de trabalho entre homens e mulheres, complementando outros indicadores de trabalho comumente utilizados. Os trabalhadores insatisfeitos na ocupação são provavelmente os que mais contribuem para o aumento da rotatividade no mercado de trabalho, sendo mais vulneráveis ao desemprego, à inatividade ou à inserção de forma autônoma. Utilizaremos como proxy para a não satisfação no trabalho a variável que identifica se o indivíduo ocupado tomou alguma providência para conseguir trabalho. Nossos resultados mostram que a insatisfação no trabalho é um determinante importante da probabilidade de o trabalhador ficar inativo ou desempregado e de transitar para uma ocupação autônoma.

\section{Abstract}

International literature presents evidence that measures of no job satisfaction can serve as good predictors for labor market exits. Thus, these measures could be also important to the understanding of the differences of mobility in the labor market between men and women, complementing other indicators commonly used in literature, such as labor income, unemployment, etc. Workers classified as unsatisfied in the occupation are probably those who contribute most to the turnover in labor market, being more vulnerable to unemployment, inactivity or self-employment. As proxy for non satisfaction at work, we apply the variable that identifies if individual occupied has taken any measure to get work. The results show that satisfaction at work is an important determinant of the probability of unemployment or inactivity and self-employment. Moreover, gender seems important to determine the transition to inactivity and unemployment, but not for self-employment when the worker is dissatisfied. 


\section{1_Introdução}

Existem evidências na literatura internacional de que medidas de não satisfação no trabalho podem funcionar como boas preditoras para as saídas do mercado de trabalho (Akerlof et al., 1988; Vasileiou; Theodossiou, 2007; Sousa-Poza; Sousa-Poza, 2007). Trabalhadores menos satisfeitos no trabalho possuem maior risco de perder a sua ocupação. Por outro lado, o risco de perda de ocupação também tem forte efeito no quanto os trabalhadores se sentem satisfeitos no trabalho. Determinadas características dos trabalhadores e de sua ocupação também são fundamentais para a compreensão dos motivos pelos quais as pessoas estão ou não satisfeitas com o trabalho que possuem.

Desta forma, tais medidas seriam também informativas para o entendimento das diferenças de mobilidade no mercado de trabalho entre homens e mulheres, complementando outros indicadores comumente utilizados na literatura, tais como rendimento do trabalho, desemprego, etc. A satisfação no trabalho pode ser vista como um indicador da qualidade do casamento entre trabalhador e posto de trabalho, reunindo dimensões quantificáveis como renda e jornada, mas também questões subjetivas.

Existe vasta literatura que relaciona a satisfação no trabalho, normalmente mensurada com indicadores subjetivos de avaliação das condições do trabalho, com as características socioeconômicas dos indivíduos (Clark, 1997; Kaiser, 2002; Clark; Oswald, 1996 dentre outros)). Especificamente com relação ao sexo, os artigos mostram que as mulheres possuem níveis mais altos de satisfação no trabalho do que os homens.

No caso brasileiro, não há literatura específica sobre o tema, principalmente em razão da inexistência de dados subjetivos sobre a satisfação no trabalho, como utilizados nos estudos de outros países. No entanto, os dados da Pesquisa Mensal do Emprego (PME/IBGE) permitem avaliar a satisfação objetiva do trabalhador, tendo em vista que, cada indivíduo que trabalha, é questionado se tomou alguma providência para conseguir outro trabalho. Ou seja, a PME investiga a procura de ocupação mesmo para os trabalhadores ocupados. Os dados dessa pesquisa estão disponíveis mensalmente, a partir de 2002, para as seis principais regiões metropolitanas brasileiras. Além disto, tal pesquisa tem caráter longitudinal, já que os mesmos domicílios são entrevistados por oito meses, o que permitirá a construção de uma análise de painel. Pelas suas informações, também é possível traçar um perfil dos trabalhadores não satisfeitos com sua ocupação e identificar se esse indicador de insatisfação com a ocupação influencia de forma significativa o ingresso deles no desemprego ou na inatividade, bem como na sua inserção de forma autônoma na atividade econômica.

Para atingir tais objetivos, 0 artigo se divide em cinco partes, contando com esta introdutória e as considerações finais. A próxima seção apresenta os principais aspectos da base de dados e a análise descritiva dos indicadores utilizados. Em seguida, abordamos o modelo teórico de satisfação no trabalho. Na quarta seção, mostramos a estratégia econométrica, e, na seção 5, os principais resultados encontrados.

\section{2_Base de dados e análise descritiva}

\section{1_A base de dados}

A base de dados utilizada no artigo é a Pesquisa Mensal do Emprego (PME/IBGE), no período de 2002 a 2007. ${ }^{1}$

Conforme IBGE (2002), a PME é uma pesquisa domiciliar de periodicidade mensal e que apresenta um esquema de rotação de domicílios mensal e uma estrutura de painel. Essas características da PME, por um lado, permitem 
a existência de sobreposição amostral mensal, garantindo a precisão das estimativas mensais dos principais indicadores que descrevem o mercado de trabalho brasileiro. Por outro, a PME pode ser classificada como uma pesquisa de caráter longitudinal, na qual os mesmos domicílios são entrevistados por quatro meses consecutivos, saem da amostra pelos oito meses seguintes e retornam novamente para a amostra posteriormente por quatro meses. Logo, o domicílio pode ser acompanhado de um ano para outro, por um período de até 16 meses, entre a $1^{\mathrm{a}}$ e a última entrevista. Por exemplo, se a primeira entrevista de um domicílio é realizada em janeiro de 2003, a quinta entrevista desse domicílio será feita em janeiro de $2004 \mathrm{e}$ assim por diante, até abril de 2004. A identificação das pessoas no domicílio é feita valendo-se das informações disponíveis sobre dia, mês e ano de nascimento e sexo. ${ }^{2}$

Neste artigo, como o interesse é a relação entre a satisfação no trabalho e algumas outras variáveis relacionadas às características individuais dos trabalhadores e de suas ocupações, a subamostra da PME é delimitada aos trabalhadores de 25 a 65 anos de idade 3 ocupados na semana de referência, totalizando 162.876 observações.

Como no Brasil não existem pesquisas específicas sobre o grau de satisfação no trabalho, ${ }^{4}$ utilizaremos com proxy desse a pergunta da PME/IBGE que identifica se o trabalhador ocupado na semana de referência tinha tomado alguma providência para conseguir outro trabalho no período de referência de 365 dias. Essa pergunta é feita para todos os trabalhadores ocupados na semana de referência, e, caso ele responda que tomou providência, é investigada a última providência (se consultou empregadores, se realizou concursos, etc.) e o período no qual realizou tal providência (nos últimos 7 dias ou 23 dias, etc.). Caso ele responda que não tomou nenhuma providência, a entrevista é encerrada.
A procura por outra ocupação é um dos indicativos de que o trabalhador não está alocado da forma que deseja, refletindo uma insatisfação com relação ao posto de trabalho que ocupa e também com a perspectiva de encontrar alternativas melhores de ocupação. ${ }^{5}$ De acordo com Machado e Machado (2007), uma pessoa pode estar na condição de subocupada se deseja encontrar alguma ocupação alternativa a que possui e nela se engajar. Se estiver subocupada, significa que sua capacidade produtiva estaria sendo subaproveitada, uma vez que estaria melhor em outro tipo de trabalho. Portanto, existe relação entre pessoas não satisfeitas com o trabalho e o grau de rotatividade dentro do mercado de trabalho.

Por intermédio desse banco de dados, vamos analisar a mobilidade na parte descritiva, desagregando por sexo, das pessoas que estavam "satisfeitas" ou "insatisfeitas" na ocupação da semana de referência, conforme nosso indicador proxy de satisfação no trabalho. Construímos tabelas de mobilidade dos trabalhadores, em que a situação de origem define se o trabalhador está ou não satisfeito com o trabalho (primeira entrevista). A situação de destino (quinta entrevista) estabelece a mudança da sua situação no mercado de trabalho.

A análise econométrica (seção 3 ) está dividida em três partes. Inicialmente, vamos estudar os principais fatores que afetam a probabilidade de os trabalhadores estarem ou não satisfeitos com a sua ocupação. Separamos esses fatores em dois grupos:

1_ Características do trabalhador: sexo, idade, proxy da experiência (idade elevada ao quadrado), se chefe de família, região metropolitana onde o domicílio da pessoa está localizado;

2_ Características da ocupação do trabalhador: tempo de permanência na sua ocupação atual, de forma a descrever algo sobre instabilidade na ocupação 
(igual a 1 , se 0 trabalhador estiver há menos de um ano na ocupação, e zero, caso contrário), posição na ocupação, total de horas habituais que trabalha na semana, rendimento horário habitual mensal e setor de atividade da sua ocupação.

Na segunda parte, vamos identificar se o grau de insatisfação no trabalho é fator importante para determinar a saída da atividade econômica (inatividade) ou o ingresso no desemprego, e se esse efeito é diferenciado entre homens e mulheres. Esse corte por sexo é importante, tendo em vista que, segundo a literatura internacional, há enorme discussão sobre as preferências de homens e mulheres com relação à inserção no mercado de trabalho, sobretudo no que tange a sua permanência, caso ocorra insatisfação na ocupação.

Nesta parte, também vamos fazer uma análise da probabilidade de o trabalhador se inserir de forma autônoma na atividade econômica, seja como trabalhador por conta própria, seja como empregador, na hipótese de estar insatisfeito com seu emprego. Há, na literatura brasileira, artigos que enfatizam que o trabalhador por conta própria ou o empregador muitas vezes escolhe se inserir dessa forma na atividade econômica por vontade própria (Machado; Fontes, 1999; Pero; Urani, 1993). Pela análise de transição, poderemos identificar se o grau de insatisfação tem efeito significativo nessa probabilidade e se existem diferenças com relação ao sexo do trabalhador.

\section{2_Análise descritiva}

Como pode ser visto na Tabela 1, cerca de $8 \%$ do total de ocupados de 25 a 65 anos de idade são considerados como não satisfeitos com a ocupação, tendo em vista que, mesmo ocupados, tomaram providências para conseguir outro trabalho. Esse percentual difere um pouco para homens e mulheres. Enquanto 7,6\% dos homens ocupados decla- raram tomar providência para conseguir outra ocupação, no que diz respeito às mulheres, esse percentual sobe 0,6 pontos percentuais, chegando a $8,3 \%$.

O percentual de mulheres que gostaria de trabalhar além do número de horas efetivamente trabalhado é, por sua vez, mais alto do que o dos homens (10,8\% contra $8,6 \%$, respectivamente). Em geral, as trabalhadoras inserem-se em ocupações com jornadas de trabalho inferiores a dos homens, portanto, muitas ainda possuem margem de manobra para o aumento do tempo de trabalho, caso queiram. Embora exista alguma interseção entre esses dois indicadores, esses podem ser vistos como complementares para a análise da satisfação no trabalho. A busca por outra ocupação não está necessariamente relacionada à subocupação no sentido de horas trabalhadas.

Tabela 1_Indicador de satisfação no trabalho por gênero

\begin{tabular}{|c|c|c|c|}
\hline & Homem & Mulher & Total \\
\hline \multicolumn{4}{|c|}{ Tomou providência para conseguir outro trabalho } \\
\hline \multirow[t]{2}{*}{ Sim } & 4.536 & 3.957 & 8.493 \\
\hline & $7,6 \%$ & $8,3 \%$ & $7,9 \%$ \\
\hline \multirow[t]{2}{*}{ Não } & 54.801 & 43.772 & 98.573 \\
\hline & $92,4 \%$ & $91,7 \%$ & $92,1 \%$ \\
\hline Total de ocupados & 59.337 & 47.729 & 107.066 \\
\hline \multicolumn{4}{|c|}{ Gostaria de trabalhar além do número de horas efetivamente trabalhadas } \\
\hline \multirow[t]{2}{*}{ Sim } & 5.128 & 5.156 & 10.284 \\
\hline & $8,6 \%$ & $10,8 \%$ & $9,6 \%$ \\
\hline \multirow[t]{2}{*}{ Não } & 54.315 & 42.621 & 96.936 \\
\hline & $91,4 \%$ & $89,2 \%$ & $90,4 \%$ \\
\hline Total & 59.443 & 47.777 & 107.220 \\
\hline
\end{tabular}

Fonte: PME/IBGE, 2002 a 2007

A Tabela 2 mostra alguns resultados sobre a mobilidade dos trabalhadores para dentro e fora da força de trabalho (população economicamente ativa) no período de 12 meses, 
segundo a situação de satisfação com relação à ocupação na primeira entrevista. Todos os trabalhadores estavam ocupados no início do período, sendo investigada a sua situação final, em termos de inserção na força de trabalho, no $12^{\circ}$ mês após a $1^{\mathrm{a}}$ entrevista.

Existiam, portanto, cerca de 59,3 mil trabalhadores ocupados homens e 47,7 mil ocupados mulheres durante a $1^{\mathrm{a}}$ entrevista. Desse total, 98,6 mil trabalhadores de ambos os sexos consideravam sua ocupação satisfatória, tendo em vista que não tomaram nenhuma providência para conseguir outro trabalho. Como pode ser visto na Tabela 2, do total de trabalhadores satisfeitos com a ocupação, $92 \%$ permanecem na força de trabalho, seja como ocupados ( $89 \%$ ), seja à procura de um trabalho (3\%). Desagregando tal informação por sexo, conforme esperado, verificamos que esse percentual de permanência na força de trabalho é menor para as mulheres, isto é, $89 \%$ delas ficam na PEA, 12 meses após a $1^{a}$ entrevista. Para os homens, tal percentual é de $95 \%$.

As diferenças entre os sexos ficam mais evidentes quando observamos a mobilidade dos trabalhadores para a situação de inatividade. A porcentagem total de mulheres que trabalhava durante a realização da primeira entrevista e que deixava de trabalhar (tornava-se inativa) na entrevista ocorrida nos 12 meses seguintes era de $12 \%$. Esse resultado é esperado tendo em vista que a inserção feminina muitas vezes não é adequada às suas preferências ou a de seus empregadores. No conjunto de mulheres "insatisfeitas" com a inserção na atividade econômica, 14\% tornaram-se inativas no período posterior. Para as mulheres "satisfeitas", esse percentual é de $11 \%$. Nos homens, tal percentual de saída da força de trabalho é bem mais baixo: $5 \%$, tanto para os homens "insatisfeitos" como para os "satisfeitos” com a ocupação.

Outra questão é se a insatisfação com relação ao trabalho no momento de realização da $1^{\mathrm{a}}$ entrevista levou a
Tabela 2_Trabalhadores ocupados segundo a situação no mercado de trabalho 12 meses depois

\begin{tabular}{|c|c|c|c|}
\hline & Homem & Mulher & Total \\
\hline Total & 59.337 & 47.729 & 107.066 \\
\hline \multirow[t]{2}{*}{ Ocupado } & 54.531 & 40.663 & 95.194 \\
\hline & $91,9 \%$ & $85,2 \%$ & $88,9 \%$ \\
\hline \multirow[t]{2}{*}{ Desempregado } & 1.750 & 1.503 & 3.253 \\
\hline & $2,9 \%$ & $3,1 \%$ & $3,0 \%$ \\
\hline \multirow[t]{2}{*}{ Inativo } & 3.056 & 5.563 & 8.619 \\
\hline & $5,2 \%$ & $11,7 \%$ & $8,1 \%$ \\
\hline Insatisfeitos & 4.536 & 3.957 & 8.493 \\
\hline \multirow[t]{2}{*}{ Ocupado } & 4.009 & 3.118 & 7.127 \\
\hline & $88,4 \%$ & $78,8 \%$ & $83,9 \%$ \\
\hline \multirow[t]{2}{*}{ Desempregado } & 294 & 303 & 597 \\
\hline & $6,5 \%$ & $7,7 \%$ & $7,0 \%$ \\
\hline \multirow[t]{2}{*}{ Inativo } & 233 & 536 & 769 \\
\hline & $5,1 \%$ & $13,5 \%$ & $9,1 \%$ \\
\hline Satisfeitos & 54.801 & 43.772 & 98.573 \\
\hline \multirow[t]{2}{*}{ Ocupado } & 50.522 & 37.545 & 88.067 \\
\hline & $92,2 \%$ & $85,8 \%$ & $89,3 \%$ \\
\hline \multirow[t]{2}{*}{ Desempregado } & 1.456 & 1.200 & 2.656 \\
\hline & $2,7 \%$ & $2,7 \%$ & $2,7 \%$ \\
\hline \multirow[t]{2}{*}{ Inativo } & 2.823 & 5.027 & 7.850 \\
\hline & $5,2 \%$ & $11,5 \%$ & $8,0 \%$ \\
\hline
\end{tabular}

Fonte: PME/IBGE, 2002 a 2007.

uma mudança na posição na ocupação, 12 meses depois. A mobilidade dos trabalhadores insatisfeitos (total, homens e mulheres) pode ser verificada na Tabela 3 , que deve ser lida da seguinte forma: na linha, temos a situação dos trabalhadores no momento da $1^{\text {a }}$ entrevista e, na coluna, a situação dos trabalhadores no mercado de trabalho 12 meses depois. Por conta disso, acrescentamos outras duas possi- 
bilidades de transição: a inatividade ou o desemprego. A maior parte dos trabalhadores que se diziam insatisfeitos no momento de realização da $1^{\mathrm{a}}$ entrevista estava inserida no mercado de trabalho, de forma autônoma (33,4\%). Para homens e mulheres, isso também acontecia, sendo o percentual mais elevado para os primeiros (38,2\% contra $27,9 \%$, respectivamente). Desses trabalhadores, 12 meses depois, notamos que a maior parte deles, tanto para o total quanto de forma desagregada para homens e mulheres, permanece na situação original de trabalhador por conta própria.

Para os homens, $14,0 \%$ e 11,5\% desses trabalhadores, ingressam no emprego com carteira de trabalho e sem ela, respectivamente, 12 meses depois. Apenas $12 \%$ aproximadamente sai da atividade econômica, seja para a inatividade $(6,3 \%)$, seja para o desemprego $(6,3 \%)$. No caso das mulheres, o movimento é diferente. Primeiro, é interessante notar que há menor percentual de insatisfação, conforme dito e, segundo que, aquelas que estavam insatisfeitas no momento de realização da $1^{\mathrm{a}}$ entrevista acabam indo para a inatividade (19\%) ou para o desemprego (8\%).

A maioria dos trabalhadores insatisfeitos no momento de realização da $1^{\text {a }}$ entrevista e que eram funcionários públicos $(5,2 \%$ do total de insatisfeitos) ou empregados registrados (26\% do total de insatisfeitos) permanece no mesmo tipo de ocupação.

Como pode ser visto na Tabela 3 , do total de trabalhadores ocupados no funcionalismo público, cerca de $71 \%, 12$ meses depois, permaneceu na mesma posição na ocupação. Para homens, esse percentual foi de $66,9 \%$, e, para as mulheres, um pouco superior, $73,3 \%$. Quando tais trabalhadores mudam de posição, a maior parte vai para o emprego com carteira assinada.

Para o total de empregados com carteira de trabalho assinada insatisfeitos no momento de realização da $1^{\mathrm{a}}$ entrevista, $73,9 \%$ permaneceram nessa mesma posição na ocupação, 12 meses depois. Para os homens e as mulheres, respectivamente, esses valores foram de $75,6 \%$ e $71,6 \%$. Se não permanecem como empregados formalmente, migram para empregos sem carteira assinada. Os homens também migram para trabalho por conta própria e desemprego. Já as mulheres migram também para desemprego e inatividade.

As maiores transições ocorrem quando os trabalhadores insatisfeitos estavam inseridos em ocupações de baixa qualidade, como empregados sem carteira de trabalho assinada ou em trabalhos domésticos. Isso é um indicativo que não somente os trabalhadores podem estar insatisfeitos com a ocupação, mas igualmente que o mercado de trabalho pode não estar oferecendo alternativas melhores para inserção desse trabalhador.

Cerca de 39,4\% dos empregados sem carteira assinada no momento de realização da $1^{a}$ entrevista permanecem nesse tipo de inserção, 12 meses depois, enquanto 21,9\% mudam para ocupações com carteira de trabalho assinada. Destaca-se que a mobilidade para o desemprego desses trabalhadores no ano seguinte à $1^{\mathrm{a}}$ entrevista é maior entre todas as posições na ocupação ( $9 \%$ deles entram no desemprego).

As diferenças por sexo mostram que a transição do emprego sem carteira assinada para o desemprego é menor para os homens $(7,9 \%)$; contudo, a permanência no emprego sem carteira assinada é maior (41,3\%). Já para as mulheres, encontramos menor percentual de empregadas sem carteira de trabalho assinada insatisfeitas que ficam em tal posição, 12 meses depois (36,5\%). Dessas, 18,4\% migram para o emprego com carteira assinada. Há também transição maior do que dos homens para o desemprego e a inatividade. Cerca de 10,7\% das mulheres empregadas sem carteira assinada insatisfeitas migram para o desemprego. Para a inatividade, esse percentual é de $12,9 \%$. No caso dos homens, esses valores foram de $7,9 \%$ e $5,9 \%$, respectivamente, para o desemprego e a inatividade. 
Tabela 3_Trabalhadores ocupados insatisfeitos no momento de realização da 1a. entrevista segundo a situação no mercado de trabalho, 12 meses depois situação no mercado de trabalho, 12 meses depois da 1a. entrevista (coluna)

\begin{tabular}{|c|c|c|c|c|c|c|c|c|c|c|c|c|c|c|}
\hline \multirow[t]{2}{*}{$\begin{array}{l}\text { Situação no mercado de traba- } \\
\text { Iho na } 1 \mathrm{a} \text {. entrevista (linha) } \\
\ldots \ldots \ldots \ldots\end{array}$} & \multirow{2}{*}{\multicolumn{2}{|c|}{ Desempregados }} & \multicolumn{2}{|c|}{ Inativos } & \multicolumn{2}{|c|}{$\begin{array}{l}\text { Funcionários } \\
\text { públicos }\end{array}$} & \multicolumn{2}{|c|}{$\begin{array}{l}\text { Empregados } \\
\text { com carteira } \\
\text { de trabalho } \\
\text { assinada }\end{array}$} & \multicolumn{2}{|c|}{$\begin{array}{l}\text { Empregados } \\
\text { sem carteira } \\
\text { de trabalho } \\
\text { assinada }\end{array}$} & \multicolumn{2}{|c|}{$\begin{array}{l}\text { Trabalhadores } \\
\text { domésticos }\end{array}$} & \multicolumn{2}{|c|}{$\begin{array}{l}\text { Trabalhadores } \\
\text { por conta própria }\end{array}$} \\
\hline & & & obs. & $\%$ & obs. & $\%$ & obs. & $\%$ & obs. & $\%$ & obs. & $\%$ & obs. & $\%$ \\
\hline Total & 597 & 7,0 & 769 & 9,1 & 460 & 5,4 & 2452 & 28,9 & 1323 & 15,6 & 580 & 6,8 & 2069 & 24,4 \\
\hline funcionários públicos & 7 & 1,6 & 9 & 2,0 & 315 & 70,9 & 66 & 14,9 & 36 & 8,1 & 2 & 0,5 & 8 & 1,8 \\
\hline $\begin{array}{l}\text { empregados com carteira } \\
\text { de trabalho assinada }\end{array}$ & 146 & 6,6 & 101 & 4,6 & 64 & 2,9 & 1630 & 73,9 & 147 & 6,7 & 16 & 0,7 & 92 & 4,2 \\
\hline $\begin{array}{l}\text { empregados sem carteira } \\
\text { de trabalho assinada }\end{array}$ & 173 & 8,9 & 166 & 8,6 & 62 & 3,2 & 423 & 21,9 & 762 & 39,4 & 39 & 2,0 & 268 & 13,9 \\
\hline trabalhadores domésticos & 57 & 7,3 & 138 & 17,6 & 4 & 0,5 & 44 & 5,6 & 38 & 4,8 & 443 & 56,5 & 58 & 7,4 \\
\hline trabalhadores por conta própria & 197 & 6,9 & 329 & 11,6 & 11 & 0,4 & 257 & 9,1 & 313 & 11,0 & 77 & 2,7 & 1562 & 55,0 \\
\hline empregadores & 8 & 3,7 & 11 & 5,1 & 3 & 1,4 & 22 & 10,3 & 21 & 9,8 & 2 & 0,9 & 66 & 30,8 \\
\hline trabalhadores não remunerados & 9 & 12,5 & 15 & 20,8 & 1 & 1,4 & 10 & 13,9 & 6 & 8,3 & 1 & 1,4 & 15 & 20,8 \\
\hline Homens & 294 & 6,5 & 233 & 5,1 & 169 & 3,7 & 1484 & 32,7 & 842 & 18,6 & 27 & 0,6 & 1311 & 28,9 \\
\hline funcionários públicos & 1 & 0,6 & 2 & 1,2 & 109 & 66,9 & 33 & 20,2 & 11 & 6,7 & 0 & 0,0 & 6 & 3,7 \\
\hline $\begin{array}{l}\text { empregados com carteira } \\
\text { de trabalho assinada }\end{array}$ & 75 & 6,1 & 41 & 3,3 & 28 & 2,3 & 936 & 75,6 & 79 & 6,4 & 4 & 0,3 & 68 & 5,5 \\
\hline $\begin{array}{l}\text { empregados sem carteira } \\
\text { de trabalho assinada }\end{array}$ & 94 & 7,9 & 71 & 5,9 & 22 & 1,8 & 287 & 24,0 & 493 & 41,3 & 7 & 0,6 & 194 & 16,2 \\
\hline trabalhadores domésticos & 2 & 8,0 & 2 & 8,0 & 0 & 0,0 & 7 & 28,0 & 2 & 8,0 & 7 & 28,0 & 4 & 16,0 \\
\hline trabalhadores por conta própria & 109 & 6,3 & 109 & 6,3 & 7 & 0,4 & 199 & 11,5 & 242 & 14,0 & 9 & 0,5 & 985 & 56,8 \\
\hline empregadores & 8 & 5,2 & 4 & 2,6 & 2 & 1,3 & 17 & 11,1 & 14 & 9,2 & 0 & 0,0 & 47 & 30,7 \\
\hline trabalhadores não remunerados & 5 & 17,9 & 4 & 14,3 & 1 & 3,6 & 5 & 17,9 & 1 & 3,6 & 0 & 0,0 & 7 & 25,0 \\
\hline Mulheres & 303 & 7,7 & 536 & 13,5 & 291 & 7,4 & 968 & 24,5 & 481 & 12,2 & 553 & 14,0 & 758 & 19,2 \\
\hline funcionários públicos & 6 & 2,1 & 7 & 2,5 & 206 & 73,3 & 33 & 11,7 & 25 & 8,9 & 2 & 0,7 & 2 & 0,7 \\
\hline $\begin{array}{l}\text { empregados com carteira } \\
\text { de trabalho assinada }\end{array}$ & 71 & 7,3 & 60 & 6,2 & 36 & 3,7 & 694 & 71,6 & 68 & 7,0 & 12 & 1,2 & 24 & 2,5 \\
\hline $\begin{array}{l}\text { empregados sem carteira } \\
\text { de trabalho assinada }\end{array}$ & 79 & 10,7 & 95 & 12,9 & 40 & 5,4 & 136 & 18,4 & 269 & 36,4 & 32 & 4,3 & 74 & 10,0 \\
\hline trabalhadores domésticos & 55 & 7,2 & 136 & 17,9 & 4 & 0,5 & 37 & 4,9 & 36 & 4,7 & 436 & 57,4 & 54 & 7,1 \\
\hline trabalhadores por conta própria & 88 & 8,0 & 220 & 19,9 & 4 & 0,4 & 58 & 5,2 & 71 & 6,4 & 68 & 6,2 & 577 & 52,2 \\
\hline empregadores & 0 & 0,0 & 7 & 11,5 & 1 & 1,6 & 5 & 8,2 & 7 & 11,5 & 2 & 3,3 & 19 & 31,1 \\
\hline trabalhadores não remunerados & 4 & 9,1 & 11 & 25,0 & 0 & 0,0 & 5 & 11,4 & 5 & 11,4 & 1 & 2,3 & 8 & 18,2 \\
\hline
\end{tabular}


Tabela 3_Trabalhadores ocupados insatisfeitos no momento de realização da 1a. entrevista segundo a situação no mercado de trabalho, 12 meses depois situação no mercado de trabalho, 12 meses depois da 1a. entrevista (coluna)

\begin{tabular}{|c|c|c|c|c|c|c|}
\hline $\begin{array}{l}\text { Situação no mercado de traba- } \\
\text { Iho na 1a. entrevista (linha) }\end{array}$ & \multicolumn{2}{|c|}{ Empregadores } & \multicolumn{2}{|c|}{$\begin{array}{l}\text { Trabalhadores não } \\
\text { remunerados }\end{array}$} & \multicolumn{2}{|l|}{ Total } \\
\hline Total & 215 & 2,5 & 28 & 0,3 & 8493 & 100,0 \\
\hline funcionários públicos & 1 & 0,2 & 0 & 0,0 & 444 & 100,0 \\
\hline $\begin{array}{l}\text { empregados com carteira } \\
\text { de trabalho assinada }\end{array}$ & 10 & 0,5 & 1 & 0,0 & 2207 & 100,0 \\
\hline $\begin{array}{l}\text { empregados sem carteira } \\
\text { de trabalho assinada }\end{array}$ & 35 & 1,8 & 5 & 0,3 & 1933 & 100,0 \\
\hline trabalhadores domésticos & 2 & 0,3 & 0 & 0,0 & 784 & 100,0 \\
\hline trabalhadores por conta própria & 85 & 3,0 & 8 & 0,3 & 2839 & 100,0 \\
\hline empregadores & 79 & 36,9 & 2 & 0,9 & 214 & 100,0 \\
\hline trabalhadores não remunerados & 3 & 4,2 & 12 & 16,7 & 72 & 100,0 \\
\hline Homens & 167 & 3,7 & 9 & 0,2 & 4536 & 100,0 \\
\hline funcionários públicos & 1 & 0,6 & 0 & 0,0 & 163 & 100,0 \\
\hline $\begin{array}{l}\text { empregados com carteira } \\
\text { de trabalho assinada }\end{array}$ & 7 & 0,6 & 0 & 0,0 & 1238 & 100,0 \\
\hline $\begin{array}{l}\text { empregados sem carteira } \\
\text { de trabalho assinada }\end{array}$ & 24 & 2,0 & 3 & 0,3 & 1195 & 100,0 \\
\hline trabalhadores domésticos & 1 & 4,0 & 0 & 0,0 & 25 & 100,0 \\
\hline trabalhadores por conta própria & 72 & 4,2 & 2 & 0,1 & 1734 & 100,0 \\
\hline empregadores & 61 & 39,9 & 0 & 0,0 & 153 & 100,0 \\
\hline trabalhadores não remunerados & 1 & 3,6 & 4 & 14,3 & 28 & 100,0 \\
\hline Mulheres & 48 & 1,2 & 19 & 0,5 & 3957 & 100,0 \\
\hline funcionários públicos & 0 & 0,0 & 0 & 0,0 & 281 & 100,0 \\
\hline $\begin{array}{l}\text { empregados com carteira } \\
\text { de trabalho assinada }\end{array}$ & 3 & 0,3 & 1 & 0,1 & 969 & 100,0 \\
\hline $\begin{array}{l}\text { empregados sem carteira } \\
\text { de trabalho assinada }\end{array}$ & 11 & 1,5 & 2 & 0,3 & 738 & 100,0 \\
\hline trabalhadores domésticos & 1 & 0,1 & 0 & 0,0 & 759 & 100,0 \\
\hline trabalhadores por conta própria & 13 & 1,2 & 6 & 0,5 & 1105 & 100,0 \\
\hline empregadores & 18 & 29,5 & 2 & 3,3 & 61 & 100,0 \\
\hline trabalhadores não remunerados & 2 & 4,5 & 8 & 18,2 & 44 & 100,0 \\
\hline
\end{tabular}

Fonte: PME/IBGE, 2002 a 2007 


\section{3_Modelo teórico}

Existe uma vertente na economia que estuda o bem-estar social por meio do uso de medidas subjetivas sobre a satisfação pessoal. Uma dessas medidas de satisfação pessoal está relacionada ao trabalho do indivíduo. Logo, a utilidade individual poderia ser representada por uma função utilidade com diferentes componentes, na qual cada componente estaria relacionado a uma área específica da vida do indivíduo. Por exemplo, a utilidade derivada de ter uma família, ou a utilidade derivada de ter uma ocupação. Seguindo Clark e Oswald (1996), teríamos uma função utilidade total dividida em outras funções "subutilidade":

$$
v=v(u, \mu)
$$

Onde $\mu$ seria a componente que agregaria as subutilidades advindas de diversas outras áreas da vida do indivíduo, enquanto $u$ representaria a utilidade advinda do trabalho do indivíduo.

Em economia do trabalho, usualmente, não se descreve que o trabalho gera utilidade, mas apenas desutilidade (Borjas, 1996). Entretanto, existem vários trabalhos que mostram que o trabalhador pode ter determinado grau de satisfação no trabalho. Esse seu grau de satisfação depende de condições implícitas a sua ocupação, tais como o rendimento, a sua jornada de trabalho, as formas de contratação (se é um empregado formal) e ao ambiente de trabalho (se trabalha sozinho ou em equipe, se a empresa tem muitos ou poucos funcionários, etc.). A satisfação no trabalho, portanto, poderia ser uma proxy para a utilidade que o trabalhador tem na sua atividade econômica.

A utilidade no trabalho é usualmente considerada como sendo da seguinte forma:

$$
u=u(y, h, i, j)
$$

Onde $y$ é o rendimento do trabalho, $h$ é a jornada do trabalho, $i$ e $j$ representariam as características individuais e específicas da ocupação do indivíduo, respectivamente.

A análise da relação desses fatores com o grau de insatisfação no trabalho é importante, uma vez que serve como um "termômetro" do comportamento do trabalhador em relação à sua atividade, bem como da relação entre esse e seu empregador. $O$ fato de um trabalhador estar insatisfeito ou não com o seu emprego pode ser explicado por inúmeros fatores, refletindo que o "casamento" ocupação-trabalhador não é perfeito. Desta forma, (o fato de um trabalhador estar procurando uma nova ocupação é um indicativo de saídas futuras e do possível aumento da rotatividade no mercado de trabalho.

Como descrito na eq. (2), acima, as características individuais influenciam o grau de satisfação alcançado no trabalho. Um trabalhador mais escolarizado possui preferências com relação à atividade que realiza completamente diferentes de um trabalhador com menor grau de instrução. Isso advém não apenas do seu diferencial de produtividade, traduzido principalmente no quanto ganha de rendimento, mas do seu grau de realização profissional, por exemplo. Desta forma, o grau de satisfação no trabalho é influenciado por essas características individuais observadas, como também por valores subjetivos associados ao trabalho. Tais valores podem revelar prioridades e valores individuais específicos de cada um (Clark, 1997).

A mobilidade no trabalho ocorre quando a utilidade que o trabalhador adquire em determinada situação no mercado de trabalho é inferior à utilidade que poderia adquirir em outra situação. Se um trabalhador não está satisfeito com sua ocupação, ele vai procurar nova forma de se inserir no mercado de trabalho ou pode até preferir sair da força de trabalho. Essas diferenças com relação ao grau de 
satisfação do trabalhador em diferentes estados do mercado de trabalho, por sua vez, influenciam as transições ocupacionais e o fluxo de entrada e saída da força de trabalho.

\section{4_Estratégia econométrica}

Neste artigo, não temos uma medida explícita de como os trabalhadores avaliam de forma subjetiva a sua ocupação. Utilizamos a busca por uma nova ocupação de uma pessoa já inserida na atividade econômica como indicador da utilidade que tira do trabalho, e, portanto, sua satisfação. $O$ fato de o indivíduo estar procurando uma nova ocupação enquanto já ocupado, mostra que ele não está satisfeito na atividade na qual está engajado. Além disso, pode ter tido dificuldades em achar uma ocupação melhor do que a encontrada por causa do próprio funcionamento do mercado de trabalho.

Vamos estudar os aspectos que afetam esse indicador de "insatisfação" do trabalhador e se tal característica influencia de forma significativa a mobilidade desses trabalhadores no ano posterior à realização da pesquisa. Ou seja, mostraremos o efeito do indicador de insatisfação dos trabalhadores sobre a probabilidade de ficarem desempregados ou inativos e de se tornarem trabalhadores autônomos no ano seguinte e se esse efeito é diferenciado por sexo.

Esse fenômeno pode ser estudado por meio da aplicação de modelos de variáveis dependentes binárias. Na primeira parte, a variável dependente tem valor 1 para os trabalhadores ocupados insatisfeitos (tomaram providências para obter outro trabalho) e zero para os trabalhadores ocupados satisfeitos (não tomaram providências para obter outro trabalho). Investigam-se os fatores que influenciam a probabilidade de o trabalhador estar insatisfeito com a sua ocupação no momento de realização da $1^{\mathrm{a}}$ entrevista.
Na segunda parte, inicialmente analisamos a probabilidade de os trabalhadores transitarem para a situação de inatividade ou de desemprego um ano depois. A variável independente é igual a 1 (um) para os trabalhadores que ficaram desempregados ou inativos no segundo momento, e igual a zero, caso contrário.

Posteriormente, estudamos a probabilidade de os trabalhadores ocupados que não eram autônomos se tornarem autônomos ou empregadores. A variável dependente é igual a 1 para os trabalhadores que antes não eram trabalhadores por conta própria nem empregadores, mas que, no segundo momento, viraram trabalhadores por conta própria ou empregadores, e igual a zero, para o caso contrário.

Apesar de trabalhadores por conta própria e empregadores serem grupos relativamente heterogêneos em termos de grau de insatisfação, optamos por agregá-los na análise econométrica a posteriori. A ideia subjacente é que estamos identificando a probabilidade de um trabalhador insatisfeito e que não era autônomo ou empregador vir a ser autônomo ou empregador. Primeiramente, o fato de os dois grupos serem diferentes em termos de insatisfação não afeta o resultado, uma vez que a análise da insatisfação não é feita para esses dois grupos. Na $1^{\mathrm{a}}$ entrevista, computamos apenas os trabalhadores que não estavam inseridos sobre tais formas de ocupação. Segundo, a ideia é entender se a insatisfação, sobretudo de trabalhadores empregados, pode gerar o efeito de esses trabalhadores quererem transitar para ocupações que não se caracterizam pela relação patrão empregado como as ocupações por conta própria ou de empregadores.

Nessas duas partes, utilizamos o modelo econométrico probit, que, ao estimar essa probabilidade, mostra a relação entre as variáveis dependentes e as variáveis explicativas. Mediante essa análise, vamos inicialmente identificar o efeito de cada uma das variáveis explicativas separadamente, 
isolando o efeito das demais. Vamos, portanto, estimar a probabilidade descrita na eq. (3):

$$
P(y=1 / x)=G\left(\beta_{\mathrm{o}}+\beta_{1} x_{1}+\ldots+\beta_{k} x_{k}\right)
$$

Onde $0<G(z)<1$, para todos os números $z$ reais. No modeloprobit, a função não linear $G$ é função de distribuição cumulativa normal padrão $\left(G(z)=\Phi(z)=\int_{-\infty}^{z} \varphi(v) d v\right)$.

Para analisar os determinantes da satisfação no trabalho e se existem diferenças por sexo, utilizaremos as variáveis explicativas já descritas na seção 2 , relacionadas às características individuais dos trabalhadores e de sua ocupação. Os resultados dessa estimação são apresentados na Tabela 4 para a amostra total de ocupados, para os homens ocupados e para as mulheres ocupadas, separadamente.

A fim de identificar se o indicador de insatisfação no trabalho afeta de forma significativa a probabilidade de transitar para a inatividade ou para o desemprego (Tabela 5) e para o trabalho autônomo (Tabela 6), utilizamos o modelo probit e analisamos o coeficiente do indicador de insatisfação, bem como a sua interação com a variável sexo. Neste caso, controlando para diversas características, nosso interesse é mostrar se a insatisfação gera mobilidade entre os trabalhadores e se existem diferenças significativas por sexo.

\section{5_Resultados}

A Tabela 4 apresenta os coeficientes da estimação da probabilidade de o trabalhador estar insatisfeito com a sua ocupação no momento de realização da primeira entrevista. Na segunda coluna, estão os resultados para a amostra total; nas terceira e quarta colunas, os coeficientes foram estimados para homens e mulheres separadamente.
Na primeira linha da segunda coluna, verificamos que o coeficiente da dummy de gênero é positivo $(0,081)$ e estatisticamente significativo. Após os controles por características observáveis, os homens têm maior probabilidade de estarem insatisfeitos no trabalho do que as mulheres. Esse resultado está em conformidade com a literatura internacional que utiliza medidas subjetivas de avaliação das condições de trabalho. Clark (2007) aborda diferentes argumentos para o fato de as mulheres estarem mais satisfeitas do que os homens, tais como problemas relativos à seleção da amostra, ${ }^{6}$ às preferências específicas de homens e mulheres, bem como aos valores atribuídos à carreira profissional.

Analisando as demais variáveis explicativas, tanto para a amostra total quanto para as desagregações por sexo, verificamos que, em geral, não existem muitas diferenças em termos de significância ou sinal dos coeficientes.

Tanto para o total de trabalhadores como para as mulheres, ser chefe tem efeito positivo sobre a probabilidade de estar insatisfeito no trabalho. Observamos que esse efeito não é significativo para os homens, apenas para o total e para as mulheres. Provavelmente, mulheres que acumulam a função de chefe de família com o exercício de uma atividade profissional podem se sentir mais sobrecarregadas e insatisfeitas em cumprir esse duplo papel.

A variável idade tem coeficiente positivo, sugerindo que trabalhadores mais velhos têm maior probabilidade de estarem insatisfeitos com seus postos de trabalho. O coeficiente negativo do termo quadrático, entretanto, mostra que a curva de satisfação no trabalho tem o formato de $\mathrm{U}$ invertido, ou seja, aumenta até determinada idade e depois se reduz. Além disso, verificamos que o efeito parece ser maior no caso das trabalhadoras.

Para o total da amostra, o nível de escolaridade aumenta o grau de exigência dos trabalhadores. Os ocupados com mais de 4 anos de estudo têm maior probabilidade de 
Tabela 4_Resultados da estimação da probabilidade de o trabalhador estar insatisfeito com a ocupação: amostra total, homens e mulheres

\begin{tabular}{|c|c|c|c|}
\hline \multirow{2}{*}{$\begin{array}{l}\text { Variável dependente: } \\
\text { estar insatisfeito }\end{array}$} & \multicolumn{3}{|c|}{ Coeficientes } \\
\hline & Total & Homem & Mulher \\
\hline \multirow[t]{2}{*}{ Homem } & 0.081 & & \\
\hline & $(5.36)^{*}$ & & \\
\hline \multirow[t]{2}{*}{ Chefe } & 0.123 & 0.028 & 0.223 \\
\hline & $(8.76)^{*}$ ํㅡㄴ & (1.39) & $(11.33)^{* * *}$ \\
\hline \multirow[t]{2}{*}{ Idade } & 0.015 & 0.015 & 0.023 \\
\hline & $(2.74) \div$ & $(2.10) *$ & $(2.75) \%$ \\
\hline \multirow[t]{2}{*}{ Idade ao quadrado } & -0.000 & -0.000 & -0.001 \\
\hline & $(6.68) * \%$ & $(4.85) * *$ & $(5.55) * \%$ \\
\hline \multirow[t]{2}{*}{ Menos de um ano no trabalho } & 0.318 & 0.354 & 0.279 \\
\hline & $(21.15)^{*} *$ & $(17.06) * *$ & $(12.72)^{* * *}$ \\
\hline \multirow[t]{2}{*}{ Empregado informal } & 0.539 & 0.648 & 0.379 \\
\hline & $(29.91) * \%$ & $(27.23)^{* * *}$ & $(13.55)^{* * *}$ \\
\hline \multirow[t]{2}{*}{ Conta própria } & 0.541 & 0.633 & 0.397 \\
\hline & $(32.70) \div$ & {$[29.44]^{*}$} & $(14.77)^{*}$ \\
\hline \multirow[t]{2}{*}{ Empregador } & 0.064 & 0.135 & -0.029 \\
\hline & (1.85) & $(3.22) \%$ & $(0.46)$ \\
\hline \multirow[t]{2}{*}{ No. de horas trabalhadas } & -0.012 & -0.011 & -0.015 \\
\hline & $(24.32) * *$ & $(14.65)^{* * *}$ & $(20.28)^{* *}$ \\
\hline \multirow[t]{2}{*}{ Rendimento-hora } & -0.006 & -0.006 & -0.005 \\
\hline & $(17.93)^{*}$ & $(13.85)^{* * *}$ & $(10.85)^{* * *}$ \\
\hline \multirow[t]{2}{*}{ Construção } & 0.268 & 0.234 & 0.008 \\
\hline & $(9.84)^{*}$ 前 & {$[7.41] * *$} & $(0.08)$ \\
\hline \multirow[t]{2}{*}{ Comércio } & 0.098 & 0.064 & 0.097 \\
\hline & $(4.52) * *$ & (2.21)* & $(2.87) * \%$ \\
\hline \multirow[t]{2}{*}{ Serviços prestados às empresas } & 0.177 & 0.191 & 0.096 \\
\hline & $(7.52)^{* * *}$ & $(6.38)^{* * *}$ & $(2.46)^{*}$ \\
\hline \multirow[t]{2}{*}{ Administração pública } & 0.201 & 0.184 & 0.137 \\
\hline & $(8.70) \div$ & $(5.42) * *$ & $(4.07) \div \%$ \\
\hline \multirow[t]{2}{*}{ Serviços domésticos } & 0.550 & & \\
\hline & $(18.67) * * *$ & & \\
\hline \multirow[t]{2}{*}{ Outros serviços } & 0.105 & 0.098 & 0.075 \\
\hline & $(4.75)$ *ㅡㄴ & $(3.35) * *$ & $(2.17)^{*}$ \\
\hline
\end{tabular}

\begin{tabular}{|c|c|c|c|}
\hline \multirow{2}{*}{$\begin{array}{l}\text { Variável dependente: } \\
\text { estar insatisfeito }\end{array}$} & \multicolumn{3}{|l|}{ Coeficientes } \\
\hline & Total & Homem & Mulher \\
\hline \multirow[t]{2}{*}{ Outras atividades } & 0.131 & 0.149 & -0.230 \\
\hline & (1.62) & (1.67) & (1.03) \\
\hline \multirow[t]{2}{*}{4 a 7 anos de estudo } & 0.071 & 0.111 & 0.029 \\
\hline & $(2.81)^{\text {前 }}$ & $(3.33) * *$ & (0.73) \\
\hline \multirow[t]{2}{*}{8 a 10 anos de estudo } & 0.082 & 0.134 & 0.032 \\
\hline & (3.05) & $(3.77)$ 羊 & $(0.76)$ \\
\hline \multirow[t]{2}{*}{11 ou mais } & 0.295 & 0.301 & 0.301 \\
\hline & $(11.48)^{* *}$ & $(8.84) * *$ & $(7.53)^{* * * \pi}$ \\
\hline \multirow[t]{2}{*}{ Salvador } & 0.241 & 0.193 & 0.287 \\
\hline & $(9.54) \div$ & $(5.54)$ * & $(7.73)^{* * * \pi}$ \\
\hline \multirow[t]{2}{*}{ Belo Horizonte } & 0.003 & -0.045 & 0.052 \\
\hline & (0.12) & (1.43) & (1.52) \\
\hline \multirow[t]{2}{*}{ Rio de Janeiro } & -0.071 & -0.095 & -0.034 \\
\hline & 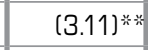 & (3.12) * & $(0.98)$ \\
\hline \multirow[t]{2}{*}{ São Paulo } & -0.136 & -0.163 & -0.104 \\
\hline & {$[5.82) * *$} & $(5.19) * *$ & $(2.95) \div$ \\
\hline \multirow[t]{2}{*}{ Porto Alegre } & -0.190 & -0.236 & -0.151 \\
\hline & $(7.51)^{* * *}$ & $(6.90)$ * & $(4.00) \div \%$ \\
\hline \multirow[t]{2}{*}{ Constante } & -1.356 & -1.343 & -1.333 \\
\hline & $(12.02) * *$ & $(8.88) \div$ & $(7.85)^{* * \ldots *}$ \\
\hline Observações & 100.242 & 55.871 & 44.371 \\
\hline
\end{tabular}

Fonte: Elaboração própria com base nos microdados da PME 2002 a 2007.

Valor absoluto da estatística $z$ em parênteses.

${ }^{*}$ significante a $5 \%$; ${ }^{* *}$ significante a $1 \%$

Nota: Os grupos de referência são: não chefe; emprego formal (empregado com carteira e funcionário público); indústria; até 3 anos de estudo; Recife

estarem em busca de outro trabalho do que os que têm menos de 4 anos de estudo. Os coeficientes encontrados foram positivos e significativos para as faixas educacionais de 4 a 7 anos de estudo $(0,071)$, de 8 a 10 anos de estudo $(0,082)$ e de 11 ou mais anos de estudo $(0,295)$. As diferenças com 
relação aos menos escolarizados são maiores para os trabalhadores com mais de 11 anos de estudo. Se, por um lado, a procura por outro trabalho indica certa insatisfação com a ocupação atual, por outro, mostra que a percepção do trabalhador é que ele pode conseguir um trabalho melhor, que tende a aumentar com a educação.

Destacamos que, para as mulheres, todos os coeficientes das faixas educacionais são positivos, mas apenas o coeficiente referente ao maior nível de escolaridade (mais de 11 anos de estudo) é significativo e igual a 0,301. Ou seja, a probabilidade de as trabalhadoras mais escolarizadas ficarem insatisfeitas com a ocupação é maior do que a das trabalhadoras que não possuem escolaridade. Tal resultado mostra que o grau de exigência com relação a uma ocupação é maior para as mais escolarizadas apenas.

No que diz respeito aos homens, o resultado é similar ao encontrado para a amostra total; contudo, os coeficientes são maiores. Um trabalhador homem que pertence a uma faixa educacional mais elevada tem probabilidade maior de estar insatisfeito com a ocupação do que um trabalhador homem com características similares, mas com menos de 4 anos de estudo.

Os trabalhadores com menos tempo de trabalho se mostram mais insatisfeitos do que os ocupados há mais de um ano no mesmo trabalho. Para o total da amostra e para os homens (coeficientes iguais a 0,318 e 0,354), esse efeito parece ser mais expressivo do que para as mulheres, em que o coeficiente ficou em torno de 0,28 . Ou seja, um trabalhador com menos de um ano no trabalho tem probabilidade maior de estar insatisfeito comparativamente a um trabalhador com mais de um ano no trabalho.

Como pode ser visto na Tabela 4, os coeficientes de ser ou não empregado sem carteira/não remunerado e trabalhador por conta própria são significativos e positivos, indicando aumento da probabilidade de insatisfação com a ocupação. Destaca-se que, entre as variáveis explicativas, os coeficientes dessas variáveis foram os mais altos para homens do que para mulheres separadamente. A informalidade, portanto, é forte indicativo de insatisfação no trabalho, principalmente para os homens.

Jornada de trabalho (total de horas trabalhadas na semana) e rendimentos-hora (em real) têm relações negativas e estatisticamente significativas com insatisfação no trabalho. $\mathrm{O}$ coeficiente da jornada de trabalho variou de $0,012 \mathrm{a}$ 0,015 negativo, dependendo da amostra analisada, ou seja, o aumento da jornada de trabalho semanal de um trabalhador reduziria a sua probabilidade de insatisfação (de um trabalhador). Esse efeito, no entanto, não teve magnitude tão expressiva se comparado com as características relativas à informalidade da ocupação (os valores dos coeficientes foram mais altos).

Já com relação ao rendimento hora, observamos que o coeficiente foi negativo e significativo (de 0,005 a 0,006). Quanto maior o nível de rendimentos, menor a probabilidade de insatisfação do trabalhador. $\mathrm{O}$ aumento de 1 real no rendimento hora do trabalhador reduziria a probabilidade de insatisfação em menos de 1 ponto percentual. Outras características do posto de trabalho como setor de atividade também exercem influência sobre a satisfação no trabalho. Todos os setores apresentam coeficientes positivos e significativos em relação à indústria (referência), com exceção do grupamento de setores "outras atividades" e do setor de construção civil para as mulheres. ${ }^{7}$

$\mathrm{Na}$ Tabela 5, estimamos os coeficientes da probabilidade de o trabalhador estar inativo ou desempregado um ano depois da realização da $1^{\mathrm{a}}$ entrevista. Como pode ser visto, o coeficiente de interesse, indicador de insatisfação com relação à ocupação no momento de realização da $1^{\mathrm{a}}$ entrevista, é positivo e significativo para todas as três especificações, não sendo muito reduzido quando os controles 
de características individuais dos trabalhadores são inseridos. Ou seja, trabalhadores insatisfeitos têm maior probabilidade de se encontrarem inativos ou desempregados no ano seguinte à realização da primeira entrevista.

Tal efeito é reduzido para os homens. Como mostra a especificação 3 , a interação como sexo é significativa e negativa. $\mathrm{O}$ grau de insatisfação no trabalho aumenta a probabilidade de inatividade e desemprego de forma menos intensa para os homens do que para as mulheres. Esse resultado mostra que as preferências com relação à permanência na ocupação e na força de trabalho diferem entre os sexos quando há insatisfação no trabalho. Como visto na análise descritiva, o percentual de mulheres insatisfeitas com a ocupação e que migram para a inatividade ou o desemprego é superior ao dos homens.

Os demais controles dessa regressão seguem os resultados esperados:

- Quanto maior o nível educacional, menor a probabilidade de ficar inativo ou desempregado;

- Para trabalhadores de faixas etárias mais avançadas, a probabilidade de ser inativo ou desempregado aumenta;

- A probabilidade de estar desempregado ou inativo é menor para os trabalhadores que moram nas regiões mais desenvolvidas economicamente, como São Paulo e Rio de Janeiro;

- Todos os trabalhadores têm probabilidade maior de ficarem inativos ou desempregados em relação aos funcionários públicos; contudo, esse efeito é mais forte para os que estavam inseridos nas ocupações de pior qualidade, como trabalhadores não remunerados ou empregados sem carteira de trabalho assinada.

Por fim, a Tabela 6 apresenta os coeficientes da probabilidade de o trabalhador abrir o próprio negócio, como conta própria ou empregador, no ano seguinte. A insatisfação com relação à ocupação no momento de realização da $1^{\mathrm{a}}$ entrevista tem efeito positivo e significativo sobre a probabilidade de o trabalhador iniciar o próprio negócio no ano posterior, como pode ser visto na primeira linha das especificações 1, 2 e 3 da Tabela 6. À medida que inserimos mais controles na regressão, esse efeito é reduzido, contudo permanece positivo e significativo.

Ao contrário do encontrado para a probabilidade de transitar para a situação de desemprego ou de inatividade, a interação da dummy de sexo com o indicador de insatisfação não foi significativa na estimação da probabilidade de o trabalhador se tornar autônomo. Ou seja, a insatisfação na ocupação não tem efeitos diferenciados para homens ou para as mulheres quando consideramos a transição para o trabalho autônomo. Apesar de os homens terem probabilidade maior de se tornarem trabalhadores autônomos do que as mulheres (já que o coeficiente da dummy que indica o sexo é positivo e significativo tanto na especificação 2 quanto na especificação 3), o efeito da insatisfação com a ocupação não reforça este efeito. Ou seja, a insatisfação com relação à ocupação parece ser muito mais importante para diferenciar homens e mulheres quando consideramos a transição para a inatividade ou para o desemprego.

As outras variáveis dessa regressão utilizadas como controle apontam para aumento da probabilidade de desenvolver atividades autônomas com o avanço da idade e menor chance de se tornar trabalhador por conta própria ou empregador com o aumento da escolaridade. Em termos regionais, a probabilidade de ser conta própria ou empregador é maior para os trabalhadores que moram em Recife (categoria omitida) comparativamente ao Rio de Janeiro e a Salvador. Para as demais regiões, não houve significância estatística a pelo menos $5 \%$. 
Tabela 5_Resultados da estimação da probabilidade de o trabalhador ficar desempregado ou inativo

(Contunua)

(Conclusão)

\begin{tabular}{|c|c|c|c|}
\hline $\begin{array}{l}\text { Variável dependente: } \\
\text { probabilidade de ficar } \\
\text { desempregado ou inativo }\end{array}$ & $\begin{array}{l}\text { Coeficientes } \\
\text { (1) }\end{array}$ & (2) & (3) \\
\hline \multirow[t]{2}{*}{ Insatisfeito } & 0.254 & 0.249 & 0.244 \\
\hline & 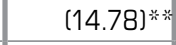 & $(14.37)$ ** & $(10.02)^{* * *}$ \\
\hline \multirow[t]{2}{*}{ Homem } & & -0.352 & -0.365 \\
\hline & & $(34.31) * *$ & $(30.98)^{* * *}$ \\
\hline \multirow[t]{2}{*}{ InsatisfeitoxHomem } & & & -0.097 \\
\hline & & & $(2.72) \%$ \\
\hline \multirow[t]{2}{*}{4 a 7 anos de estudo } & & & -0.074 \\
\hline & & & $(3.89)^{* *}$ \\
\hline \multirow[t]{2}{*}{8 a 10 anos de estudo } & & & -0.113 \\
\hline & & & $(5.48) \div$ \\
\hline \multirow[t]{2}{*}{11 anos de estudo ou mais } & & & -0.304 \\
\hline & & & $(15.89)^{* * *}$ \\
\hline \multirow[t]{2}{*}{ Idade } & & & 0.008 \\
\hline & & & $(14.93)^{* * *}$ \\
\hline \multirow[t]{2}{*}{ Salvador } & & & -0.168 \\
\hline & & & $(7.34) * *$ \\
\hline \multirow[t]{2}{*}{ Belo Horizonte } & & & -0.148 \\
\hline & & & $(7.69) \% *$ \\
\hline \multirow[t]{2}{*}{ Rio de Janeiro } & & & -0.454 \\
\hline & & & $(23.13)^{* * *}$ \\
\hline \multirow[t]{2}{*}{ São Paulo } & & & -0.264 \\
\hline & & & $(13.92) * *$ \\
\hline \multirow[t]{2}{*}{ Porto Alegre } & & & -0.153 \\
\hline & & & $(7.68)^{* *}$ \\
\hline \multirow[t]{2}{*}{ Empregado com carteira } & & & 0.528 \\
\hline & & & $(20.55)^{* * *}$ \\
\hline
\end{tabular}

\begin{tabular}{|c|c|c|c|}
\hline $\begin{array}{l}\text { Variável dependente: } \\
\text { probabilidade de ficar } \\
\text { desempregado ou inativo }\end{array}$ & $\begin{array}{l}\text { Coeficientes } \\
\text { (1) }\end{array}$ & (2) & (3) \\
\hline \multirow[t]{2}{*}{ Empregado sem carteira } & & & 0.820 \\
\hline & & & $(29.52)^{* *}$ \\
\hline \multirow[t]{2}{*}{ Trabalhador doméstico } & & & 0.641 \\
\hline & & & $(20.79)^{* * *}$ \\
\hline \multirow[t]{2}{*}{ Conta própria } & & & 0.732 \\
\hline & & & $(27.96)^{* * *}$ \\
\hline \multirow[t]{2}{*}{ Empregador } & & & 0.313 \\
\hline & & & $(9.14)^{* * *}$ \\
\hline \multirow[t]{2}{*}{ Não remunerado } & & & 0.941 \\
\hline & & & $(17.50)^{* * *}$ \\
\hline \multirow[t]{2}{*}{2003} & & & -0.059 \\
\hline & & & $(3.74)^{* * *}$ \\
\hline \multirow[t]{2}{*}{2004} & & & -0.090 \\
\hline & & & $(5.73)^{* * *}$ \\
\hline \multirow[t]{2}{*}{2005} & & & -0.104 \\
\hline & & & $(6.63)^{* *}$ \\
\hline \multirow[t]{2}{*}{2006} & & & -0.121 \\
\hline & & & $(5.96)^{* * *}$ \\
\hline \multirow[t]{2}{*}{ Constante } & -1.245 & -1.068 & -1.513 \\
\hline & $(232.82) * *$ & $(147.43) * \%$ & (34.83) $* *$ \\
\hline Observações & 107066 & 107066 & 106861 \\
\hline
\end{tabular}

Fonte: Elaboração própria com base nos microdados da PME 2002 a 2007.

Valor absoluto da estatística $\mathrm{z}$ em parênteses.

${ }^{*}$ significante a $5 \%$; ${ }^{* *}$ significante a $1 \%$

Nota: Os grupos de referência são: mulher, até 3 anos de estudo, Recife, ser funcionário público e 0 ano de 2002 
Tabela 6_Resultados da estimação da probabilidade de o trabalhador se tornar conta própria ou empregador: amostra total, homens e mulheres

(Contunua)

[Conclusão]

\begin{tabular}{|c|c|c|c|}
\hline \multirow{2}{*}{$\begin{array}{l}\text { Variável dependente: } \\
\text { probabilidade de se tornar } \\
\text { conta própria ou empregador }\end{array}$} & \multicolumn{3}{|l|}{ Coeficientes } \\
\hline & (1) & (2) & (3) \\
\hline \multirow[t]{2}{*}{ Insatisfeito } & 0.106 & 0.110 & 0.082 \\
\hline & $(4.64)^{*}$ * & $(4.78)^{* *}$ & $(2.19)^{*}$ \\
\hline \multirow[t]{2}{*}{ Homem } & & 0.196 & 0.182 \\
\hline & & $(14.43)^{* *}$ & $(12.73)^{*}$ * \\
\hline \multirow[t]{2}{*}{ InsatisfeitoxHomem } & & & 0.069 \\
\hline & & & (1.45) \\
\hline \multirow[t]{2}{*}{4 a 7 anos de estudo } & & & -0.002 \\
\hline & & & (0.08) \\
\hline \multirow[t]{2}{*}{8 a 10 anos de estudo } & & & -0.034 \\
\hline & & & $(1.26)$ \\
\hline \multirow{2}{*}{11 anos de estudo ou mais } & & & -0.128 \\
\hline & & & $(5.32) \%$ \\
\hline \multirow[t]{2}{*}{ Idade } & & & 0.026 \\
\hline & & & 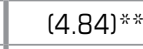 \\
\hline \multirow[t]{2}{*}{ Idade ao quadrado } & & & -0.000 \\
\hline & & & $(4.51)^{\text {并 }}$ \\
\hline \multirow[t]{2}{*}{ Salvador } & & & -0.062 \\
\hline & & & $(2.00)^{*}$ \\
\hline \multirow[t]{2}{*}{ Belo Horizonte } & & & -0.003 \\
\hline & & & $(0.11)$ \\
\hline Rio de Janeiro & & & -0.068 \\
\hline
\end{tabular}

\begin{tabular}{|c|c|c|c|}
\hline \multirow{2}{*}{$\begin{array}{l}\text { Variável dependente: } \\
\text { probabilidade de se tornar } \\
\text { conta própria ou empregador }\end{array}$} & \multicolumn{3}{|l|}{ Coeficientes } \\
\hline & (1) & (2) & (3) \\
\hline & & & $(2.69) *)^{* *}$ \\
\hline \multirow[t]{2}{*}{ São Paulo } & & & -0.005 \\
\hline & & & $(0.18)$ \\
\hline \multirow[t]{2}{*}{ Porto Alegre } & & & 0.046 \\
\hline & & & $(1.74)$ \\
\hline \multirow[t]{2}{*}{2003} & & & -0.027 \\
\hline & & & $(1.36)$ \\
\hline \multirow[t]{2}{*}{2004} & & & -0.077 \\
\hline & & & $(3.90) \%$ \\
\hline \multirow[t]{2}{*}{2005} & & & -0.060 \\
\hline & & & $(3.07)^{* * *}$ \\
\hline \multirow[t]{2}{*}{2006} & & & -0.094 \\
\hline & & & $(3.65)^{\dddot{*} *}$ \\
\hline \multirow[t]{2}{*}{ Constante } & -1.678 & -1.794 & -2.231 \\
\hline & $(243.83)^{* * *}$ & $(164.80)$ & * $\quad(19.12)^{* * *}$ \\
\hline Observações & 107100 & 107100 & 106895 \\
\hline
\end{tabular}

Fonte: Elaboração própria com base nos microdados da PME 2002 a 2007.

Valor absoluto da estatística $\mathrm{z}$ em parênteses.

* significante a $5 \%$; ${ }^{* *}$ significante a $1 \%$

Nota: Os grupos de referência são: mulher, até 3 anos de estudo,

Recife e 0 ano de 2002.

\section{6_Considerações finais}

A satisfação no trabalho é um aspecto relevante sobre a qualidade do casamento entre oferta e demanda de trabalho que explica fenômenos como desemprego e rotatividade no mercado de trabalho. No Brasil, cerca de $8 \%$ dos trabalhadores ocupados estão insatisfeitos com seus postos de trabalho, visto que buscam outra ocupação. Quando

analisamos apenas os dados descritivos da amostra, verificamos que não há diferenças significativas entre homens e mulheres em termos de incidência da "insatisfação" no mercado de trabalho. Cerca de 7,6\% dos homens tomaram providência para conseguir trabalho estando ocupados, enquanto para as mulheres esse percentual foi de $8,3 \%$. Na 
análise descritiva, também mostramos que a insatisfação com relação ao trabalho atual levou a uma mudança na posição na ocupação nos 12 meses posteriores. Os trabalhadores insatisfeitos mudam mais de ocupação, sobretudo os que estão inseridos de maneira informal no mercado de trabalho, em que o grau de permanência na mesma ocupação um ano depois é menor.

Parte dessas diferenças entre homens e mulheres no tocante à satisfação no trabalho e à posterior mudança ocupacional está sendo influenciada pelas suas características individuais e pelas ocupações nas quais estão inseridos. Mediante a análise econométrica, ao controlarmos por diversos desses fatores, mostramos que os homens têm probabilidade maior de estarem insatisfeitos com a sua ocupação do que as mulheres. $O$ coeficiente estimado da variável dummy sexo foi negativo e significativo para a amostra total.

Os resultados também mostraram que os trabalhadores inseridos na atividade econômica de forma mais precária, ou seja, com relações de trabalho informais, com rendimentos de trabalho menores, com menor tempo de permanência na ocupação, em setores tais como construção civil, são os que mais procuram por uma nova ocupação. Esses trabalhadores serão mais vulneráveis às situações de desemprego e inatividade, podendo contribuir para aumento potencial da rotatividade do mercado de trabalho.

$\mathrm{Na}$ análise econométrica, também mostramos que o grau de insatisfação com o trabalho no momento de realização da primeira entrevista tem o efeito de aumentar a probabilidade de o trabalhador ficar inativo ou desempregado 12 meses depois. Esse efeito é diferenciado para homens e mulheres, sendo mais forte para as trabalhadoras.

Já com relação à probabilidade de o trabalhador abrir o próprio negócio, seja como empregador, seja como trabalhador por conta própria, viu-se que a insatisfação tem efeito positivo. Ou seja, trabalhadores que, no momento de realização da primeira entrevista, não estavam inseridos na atividade econômica como autônomos aumentam a sua probabilidade de virarem trabalhadores por conta própria ou empregadores no ano seguinte, se estiverem insatisfeitos com o seu trabalho. Este efeito, contudo, não é diferenciado por sexo, ao contrário do resultado encontrado na transição para inatividade ou desemprego. A insatisfação com relação à ocupação parece ser muito mais importante para diferenciar homens e mulheres, quando consideramos a transição para inatividade ou para o desemprego.

\section{Notas}

\footnotetext{
${ }^{1}$ A PME/IBGE passou por profunda reformulação na sua metodologia, de forma que serão utilizados apenas os dados com a nova metodologia. Os dados da PME de 2007 compreendem o período de janeiro a agosto de 2007, já que os demais dados ainda não estavam disponíveis no momento de realização deste artigo.

${ }^{2}$ Ribas e Soares (2007) propõem um procedimento para aumentar a taxa de identificação no painel de pessoas, usando, por exemplo, a data de nascimento próxima, e não a exata. Neste artigo, entretanto, optou-se por não correr o risco de emparelhar pessoas diferentes, adotando o procedimento mais rigoroso.

${ }^{3}$ Ao delimitarmos a análise à população adulta de 25 a 65 anos de idade, esperamos minimizar os efeitos da rotatividade/ mobilidade no mercado de
}

trabalho, decorrentes da necessidade dos trabalhadores mais jovens quererem ganhar mais experiência mudando constantemente de ocupação. Quando focamos a população adulta, a rotatividade pode estar mais associada ao grau de satisfação gerado pela ocupação.

${ }^{4}$ Em vários países europeus, existem pesquisas subjetivas específicas para avaliar a satisfação dos trabalhadores com relação a vários aspectos da sua ocupação.

${ }^{5}$ Evidentemente, existe a possibilidade de o indivíduo estar insatisfeito, mas não tomar nenhuma providência para conseguir outro trabalho. Em razão até mesmo da limitação dos dados, estamos levando em consideração apenas a insatisfação que leva a uma ação de busca por trabalho. 

pré-selecionamos uma amostra de indivíduos que já se inserem no mercado de trabalho. No caso de mulheres, esse problema de seleção tende a ser ampliado. Desta forma, devemos olhar os resultados considerando tal problema, e não generalizá-los para todas as mulheres: as mulheres ocupadas já podem deter características bem particulares quando comparadas às não inseridas no mercado de trabalho.

${ }^{7}$ Nas regressões separadas de homens e mulheres, o coeficiente referente ao setor "serviços domésticos" não foi estimado tendo em vista que quase todos os trabalhadores ocupados nessa atividade são do sexo feminino ( $97 \%)$.

Borjas, G. (1996): Labor Economics, New York: McGrawHill Companies.

CLARK, A. (1997). Job satisfaction and gender: Why are women so happy at work? Labour Economics, 4, p. 341-372.

IBGE. Microdados da Pesquisa Mensal do Emprego, vários anos. 2002 a 2007.

Kaiser, L (2002). Job satisfaction: a comparison of standard, non standard and self employment patterns across Europe with a special note to the gender / job satisfaction paradox. EPAG Working Paper 27, Colchester, University of Essex.

MACHADO, D. C.; FONTES, A. F. Trabalho por conta-própria: Uma opção satisfatória para os trabalhadores da Região Metropolitana do Rio de Janeiro? Boletim O Mercado de Trabalho do Rio de Janeiro Conjuntura e Análise, Prefeitura da Cidade do Rio de Janeiro: Rio de Janeiro, v. 6, 1999.

MACHADO, D. C.; MACHADO, A. F. Um aspecto da subocupação por insuficiência de horas trabalhadas: A análise do desejo de trabalhar horas adicionais. In: ENCONTRO NACIONAL DA ASSOCIAÇÃO BRASILEIRA DE ESTUDOS DO TRABALHO, 10., 2007. Anais ... Salvador: ABET, nov. 2007.
PERO, V.; URANI, André. Os trabalhadores informais querem um emprego com contrato formal de trabalho? In: ENCONTRO DA ASSOCIAÇÃO BRASILEIRA DE ESTUDOS DO TRABALHO, 3., 1993. Anais... Rio de Janeiro: ABET, 1993.

RIBAS, R. P.; SOARES, S. S. D. (2007). Sobre o Painel da PME. Mimeo.

SOUSA-POZA, A. A.; SOUSA-POZA, A. The effect of job satisfaction on labor turnover by gender: An analysis for Switzerland. The Journal of Socio-Economics, 36, p. 895-913, 2007.

VASILEIOU, E.; THEODOSSIOU, I. Making the risk of job loss a way of life: Does if affect job satisfaction? Research in Economics, 61, p. 71-83, 2007. 